\title{
Magnetic resonance elastography demonstrates increased brain stiffness in normal pressure hydrocephalus
}

\author{
John Huston*, Avital Perry, Nikoo Fattahi, Arvin Arani, Fred Meyer, Richard Ehman \\ From Hydrocephalus 2015 \\ Banff, Canada. 18-21 September 2015
}

\section{Introduction}

Normal pressure hydrocephalus (NPH) is a potentially reversible cause of ventriculomegaly characterized by a classic triad of gait disturbance, cognitive impairment and urinary incontinence in older adults. Shunt tube placement is currently the mainstay therapy for NPH. However, unpredictable therapeutic responses as well as associated surgical complications necessitate better characterization of surgical candidates. The purpose of this study was to use MR Elastography (MRE) to determine brain tissue stiffness and outcomes after shunting in NPH patients compared with age and sex matched healthy controls.

\section{Methods}

With IRB approval 10 patients (age range of 67-79 years) with NPH who were scheduled for ventriculoperitoneal shunting underwent preoperative MRE and were correlated with 21 age- and sex-matched normal controls (age range of 67-80 years). Studies were performed on a 3T scanner with a single-shot spin-echo EPI pulse sequence. Shear waves were introduced into the brain through an external source of vibration using a frequency of $60 \mathrm{~Hz}$. We calculated the elasticity of different regions of interest (ROI) in the brain including the whole brain excluding the cerebellum (cerebrum), frontal, temporal, parietal, occipital lobes, deep grey matter/ white matter and the cerebellum. Associations between ROIs and symptoms were evaluated including cognitive decline, urinary incontinence, gait disturbance, duration of symptoms, opening pressure, improvement after lumbar puncture, and postoperative improvement. Statistical analysis included t test and linear regression.

\footnotetext{
* Correspondence: jhuston@mayo.edu Mayo Clinic, USA
} original work is properly cited. The Creative Commons Public Domain Dedication waiver (http://creativecommons.org/publicdomain/ zero/1.0/) applies to the data made available in this article, unless otherwise stated.
MRE demonstrated significantly increased parenchymal stiffness among NPH patients as compared to normal controls in multiple ROIs, including the cerebrum, occipital, and parietal lobes $(\mathrm{p}=0.042, \mathrm{p}=0.002, \mathrm{p}=0.011$ respectively). Postoperative improvement was associated with significant increased stiffness in deep grey/white matter, whereas postoperative failure was associated with significant increased temporal lobe stiffness $(p=0.013$, $\mathrm{p}=0.012$ ).

\section{Conclusions}

Brain MRE of patients with NPH revealed increased stiffness of the cerebrum, occipital and parietal lobes with a significant association between a range of NPH symptoms including the classic clinical triad with increased parenchymal stiffness. Surgically-responsive NPH was significantly associated with deep grey/white stiffness. MRE may guide selection of patients for shunting in the

Published: 18 September 2015

\section{References}

1. Arani A, Murphy MC, Glaser KJ, Manduca A, Lake DS, Kruse SA, Jack CR Jr, Ehman RL, Huston J 3rd: Measuring the effects of aging and sex on regional brain stiffness with MR elastography in healthy older adults. Neuroimage 2015, 111:59-64, Epub 2015 Feb 17. PMID:25698157. PMCID:4387012. DOI:10.1016/j.neuroimage.2015.02.016.

2. Huston J III: Magnetic Resonance Elastography of the Brain. In Magnetic Resonance Elastography. 1 edition. New York: Springer Science + Business Media;Venekatesh SK, Ehman RL 2014:89-98, DOl:10.1007/978-1-4939-1575-0_1.

doi:10.1186/2045-8118-12-S1-038

Cite this article as: Huston et al:: Magnetic resonance elastography demonstrates increased brain stiffness in normal pressure hydrocephalus. Fluids and Barriers of the CNS 2015 12(Suppl 1):038. setting of equivocal diagnoses of NPH. 